\title{
Movimento de objetivação e subjetivação mediado pela criação artística
}

\author{
Andréa Vieira Zanella ${ }^{1}$ \\ Alice Casanova dos Reis \\ Denise de Camargo \\ Kátia Maheirie \\ Kelly Bedin França \\ Silvia Zanatta Da Ros
}

\begin{abstract}
Resumo
Este texto tem por objetivo refletir sobre o movimento de um sujeito e sua relação com a criação artística, apontando que neste processo articulam-se dialeticamente o saber, o fazer e o sentir. As análises sustentam-se nas falas desse sujeito, coletadas por meio de entrevistas e registros em vídeo de sua participação em uma disciplina de um curso de graduação em Psicologia. As reflexões decorrentes, por sua vez, pautam-se nos aportes teóricos da Psicologia Histórico-Cultural e revelam a complexidade do processo de constituição do sujeito que, via atividade criadora, parte da realidade e a transforma, transformando nesse movimento a si mesmo e ao modo como significa tanto a sua própria trajetória quanto o contexto do qual ativamente participa.

Palavras-Chave: Constituição do sujeito; Atividade criadora; Criação artística; Psicologia histórico-cultural; Objetivação e subjetivação.
\end{abstract}

\section{Movement of objectivity and subjectivity, mediated for the artistic creation}

\begin{abstract}
This text has for objective reflect about the moviment of a subject and his relation with the artistic creation, aiming that in this I process articulate herself dialeticaly the knowledge, do him and feel him. Was analysed the speeches collected with interviews and records in video of his participation in a subject discipline of the one course of Psychology. The reflections was suposted by theoretical of the Historical-Cultural Psychology. Was possible reveal the complexity of the trial of constitution of the person that, road creative activity, part of the reality and it transforms, transforming in that movement to itself even and to the way as signifies so much to its own as much as path the context of which actively participates.

Keywords: Constitution of the subject; Creative activity; Artistic creation; Historical-cultural psychology; Objectivity and subjectivity.
\end{abstract}

\section{Movimento de objetivação e subjetivação mediado pela criação artística}

Neste texto a temática "constituição do sujeito" é objeto de reflexões, as quais resultam do diálogo em que falas de diferentes personagens se entrecruzam - as do sujeito estudado, as de teóricos da psicologia históricocultural e as das pesquisadoras. Nesse entrecruzar são tecidas reflexões sobre o processo de constituição de Nando (nome fictício) como sujeito envolvido com a arte, que desfruta da possibilidade de improvisar, de "recortar" significados da realidade, de imaginar, de combinar o já visto e o já dito para criar algo novo.

O marco teórico com que nossos olhos registram, analisam e informam as falas de Nando e das múltiplas vozes que, através de seu discurso, se manifestam, passa pelo entendimento do processo de constituição do sujeito em sua singularidade, como inexoravelmente social e histórico. Isso porque

[...] quando falo, ao mesmo tempo que eu, falamos "nós"; nós, a comunidade cálida da qual somos parte. Mas não há somente o "nós"; no "eu falo" também está o "se fala". Fala-se, algo anônimo, algo que é a coletividade fria. Em cada "eu" bumano há algo do "nós" e do "se". Pois o eu não é puro e não está só, nem é unico. Se não existisse o se, o eu não poderia falar. (Morin, 1996, p. 54)

Eu e outro são, nesse sentido, ao mesmo tempo, uno e diferente, singular e plural. Remetem necessariamente à dimensão relacional da própria existência humana, pois, como afirma Vygotski (1987,

\footnotetext{
${ }^{1}$ Endereço para correspondência:

Universidade Federal de Santa Catarina/Centro de Filosofia e Ciências Humanas/Pós-Graduação em Psicologia

Câmpus Universitário Trindade - 88010-970 - Florianópolis-SC

E-mail: azanella@cfh.ufsc.br
} 
p. 162) o homem, ainda que "....a sós consigo mesmo, segue funcionando em comunicação". Há muitos outros, próximos, distantes, remotos, cujas marcas nos marcam e, ressignificadas, muitos outros irão igualmente marcar. Este é o próprio movimento pelo qual culturas se instituem, cristalizam-se, transmutam.

Enfatizamos que o ser humano é produto da história ao mesmo tempo que é seu produtor. Estamos falando, pois, sobre a constituição do sujeito, sobre o modo como, via relações sociais, é produzido o conjunto de aspectos que singularizam cada ser humano e caracterizam seu modo de ser e estar no mundo.

Para que uma pessoa se constitua em quem ela é, ou seja, para que se torne um sujeito específico, é necessário vivenciar a dialética da objetivação/subjetivação (Maheirie, 2002), apropriando-se dos significados que são coletivos, tornando-os singulares para que possa objetivá-los em forma de ação, pensamento e emoções. Segundo Sartre (1984), este processo de tornar subjetivo o contexto coletivo e, em seguida, objetivar a subjetividade em um movimento de afirmação e negação do momento vivido é o que caracteriza o humano.

A psicologia histórico-cultural, desde seus primórdios, tem contribuído com explicações sobre diversos aspectos envolvidos na constituição do psiquismo humano, dentre os quais destacamos os processos psicológicos superiores. Estes processos caracterizam-se precisamente pelo fato de serem semioticamente mediados, o que possibilita ao ser humano estabelecer relações mediadas com a realidade e regular conscientemente a própria atividade (Vygotski, 1991).

Centrando suas análises no modo como paulatinamente, via apropriação da cultura, estes processos psicológicos superiores - como atenção, memória e linguagem - assim como a afetividade, vão sendo produzidos e complexificados pela mediação semiótica, Vygotski (1995) explicita de que modo se torna possível ao ser humano singularizar-se e inserir-se em contextos sociais diversos e adversos, atuando de forma deliberada ou não, orientado tanto pelas condições que encontra, quanto por um projeto particular/coletivo de futuro.

Essas ações, por sua vez, mediadas por uma determinada racionalidade (entende-se aqui racionalidade como um modo de pensar/sentir/estar no mundo, socialmente produzido), são prenhes de emoções, pois o modo como cada sujeito atua pauta-se em uma determinada leitura da realidade, e

[...] não podemos esquecer de que o indivíduo apreende a realidade a partir de uma rede de sentidos pessoais e que o faz de "forma emocionada", ou seja, atribui um sentido à realidade, sempre com alguma implicação em relação a essa. (Neves, 1997, p. 114-115)
A afetividade, tanto o sentimento como a emoção, implica necessariamente na relação com um outro, quer dizer, a afetividade é produto das relações de um sujeito em um contexto social. Sendo assim, resgatando Sartre (1965), a afetividade implica uma postura relacional não-crítica ou posicional de si, tal como Vygotski definiu o pensamento emocional em Psicologia da arte (1998). A afetividade é um modo específico de o sujeito relacionar-se, fazendo-se mediação para toda e qualquer relação que for vivenciar em determinados contextos, nesta postura já citada, necessitando dela para que possa desencadear um processo de criação.

Os sentimentos e emoções encontram na arte uma possibilidade de transformação, de superação, pois

\section{[... todo sentimento, toda emocão tende a manifestar-se em determinadas imagens concordantes com ela, como se a emo- ção pudesse eleger impressões, idéias, imagens congruentes com o estado de ânimo que nos dominasse naquele instante. (tradução nossa do espanhol, Vygotski, 1990, p. 21)}

Esclarece Vygotski (1990), no entanto, que a atividade criadora ou as manifestações artísticas não podem ser consideradas somente como meio de expressão das emoções, o que significa considerá-las como modo de objetivação da experiência humana. Essa é uma dimensão da atividade criadora que ganha visibilidade em variadas manifestações artísticas, porém essa mesma forma, em seu processo de vir a ser, subjetiva o seu autor e produz novas emoções que são por ele vividas como reais. Ao mesmo tempo em que os sentimentos movem a imaginação, a atividade imaginativa ressignifica ou produz novos sentimentos, em um movimento intenso onde emoção e pensamento se vinculam incessantemente.

Portanto, em sua forma "pura", sentimentos e emoções não produzem nada de novo. Para a criação é necessário que sejam superados, solucionados, uma vez que sozinhos não são capazes de produzir o novo. Além disso, para que haja criação é necessário todo um processo que envolve a aquisição de conhecimentos elaborados reflexivamente. Nesta perspectiva, perde-se a ilusão de que a criação possa ser um dom natural, uma dádiva "desvinculada do cotidiano e atribuída a pessoas que supostamente se encontram muito distantes da maioria da população: os gênios" (Zanella, Balbinot \& Pereira, 2000, p. 539).

O processo de criação se inicia por um resgate de conhecimentos técnicos, sua desconstrução, seu transcender no imaginário, uma reelaboração dos sentimentos e emoções, uma reconstrução dos elementos modificados "por meio da articulação entre reflexão espontânea e imaginação" (Maheirie, 2003, p. 152), para, finalmente, objetivar seu novo produto. 
Nesse sentido, o sujeito que cria reorganiza diferentes elementos oriundos de sua experiência que, em principio, não tem qualquer vínculo. A criatividade tem sua expressão máxima no processo de combinação diferenciada do que era conbecido até então, formando o novo, onde a imaginação se destaca. (Zanella e colaboradores, 2000, p. 540)

Por isso, toda atividade criadora se faz processo histórico-social, situada no tempo e no espaço, como obra social e coletiva que vai se individualizando à medida que se objetiva. O sujeito, uma vez que se faz produto e produtor do contexto social, objetiva sua subjetividade quando cria algo de novo, quando individualiza um produto, o qual foi gestado em caráter intersubjetivo. Sua história, sob esta ótica, é fundamental para a compreensão do seu processo de criação (Zanella e colaboradores, 2000), pois nela se destaca seu contexto, suas relações e, fundamentalmente, os sentidos que foi vivenciando e elegendo para que se apropriasse de uma postura criativa.

Sendo sempre compreendido de forma relacional,

\section{o processo de criação é uma articulação temporal realizada pela subjetividade, numa postura afetiva, como negação da objetividade, com vista a transformar esta objetividade numa nova objetividade, deixando nela a marca da subjetividade. (Maheirie, 2003, p. 152)}

Assim, criar nunca é uma ação desvinculada do coletivo, mas também não se faz sem um sujeito, uma subjetividade que se objetiva na necessidade, a qual se fez objetiva e subjetiva a um só tempo. Objetiva, pois a criação exige um produto, e subjetiva, pela necessidade psicológica da vivência da forma (Japiassu, 1999), da transcendência, da superação da objetividade pela subjetividade.

\section{Método}

Para esta investigação selecionamos intencionalmente um dos acadêmicos de Psicologia da Universidade Federal de Santa Catarina regularmente matriculados na disciplina optativa "Psicologia da Criatividade", oferecida no primeiro semestre do ano de 2001 por duas professoras, uma do Departamento de Psicologia e outra do Departamento de Estudos Especializados em Educação da UFSC que, ao mesmo tempo em que a ministravam, coletavam material para a pesquisa que então desenvolviam.

A concepção da disciplina, que compreendia 36 horas/aula, bem como o modo como foi proposta aos interessados, o desenvolvimento e o registro sistemático das atividades não foram casuais: desde o princípio estava claro para os participantes, professores e alunos, que naquele contexto se articulavam pesquisa e ensino, sendo o material coletado suporte para o desenvolvimento de investigações que integravam inicialmente o projeto de pesquisa "Grupo, cultura e mudança: investigando adultos escolarizados em processo de aprender" e, a partir de agosto de 2002, o projeto integrado "Constituição do sujeito e atividade criadora: investigando professores das séries iniciais do ensino fundamental em contextos de formação continuada”. As atividades didáticas compreendiam a discussão de textos e participação em oficinas estéticas, sendo questões como "criatividade" e "constituição do artista" temáticas que mobilizavam as reflexões no grupo.

O processo vivenciado foi registrado por meio de procedimentos variados: entrevistas individuais realizadas com os alunos no início e ao final do semestre letivo; filmagens em VHS de todas as aulas; arquivamento, para fins de análise, das produções artísticas dos alunos no decorrer das oficinas estéticas; elaboração individual de um portfólio, a critério dos alunos, no qual deveriam ser registrados aspectos referentes às vivências e elaborações pessoais no decorrer das aulas.

O material coletado tem sido utilizado para análise em vários recortes de pesquisa. Neste momento, estaremos utilizando as entrevistas inicial e final realizadas com um dos participantes, Nando. A escolha desse sujeito pautou-se na riqueza estética do que produzia no decorrer das aulas: em todas as suas produções, desde colagens, desenhos e esculturas, seja em papel ou argila, a sensibilidade em relação ao que era disponibilizado como material para o trabalho objetivava um modo de se relacionar com esses materiais mediado por uma percepção estética.

A percepção estética é entendida como

[...] uma atividade complexa, unitária, que não se detém na captação da aparência sensivel do objeto. Tal como a percepção comum, põe em jogo idéias, recordações, sentimentos, imagens, todos eles determinados por experiências vividas, pessoais; mas também se fazem presentes concep̧cões, valores que derivam da bagagem cultural de que se dispõe e do ideológico-estético em particular. (Sánchez Vázquez, 1999, p. 140)

Diferenciava-se assim este aluno dos demais à medida que suas produções artísticas no decorrer das oficinas revelavam uma trajetória de vida em que foi possível constituir relações estéticas com a realidade. Mas que trajetória foi essa? Quais suas peculiaridades? Quais as relações desse sujeito com a criação artística?

Para responder a essas perguntas, escolhemos a entrevista como procedimento de coleta de informações, concebendo-a como um processo de comunicação onde o entrevistador, na interação com o entrevistado, 
busca encontrar o que é significativo e importante para o informante, o modo como vê e significa o mundo, suas perspectivas e interpretações (Olabuénaga, 1999). As entrevistas seguiram um roteiro aberto, sendo as perguntas adequadas aos objetivos da investigação e modificadas no decorrer das entrevistas, de modo a não interromper o fluxo da narrativa que, no encontro com o entrevistador, era produzida.

As entrevistas foram realizadas em dois momentos, com duração aproximada de 45 minutos cada uma: no início do semestre letivo e no semestre seguinte, logo após o término da disciplina Psicologia da Criatividade. Foram previamente agendadas e realizadas nas dependências da universidade, em local definido conjuntamente pelo sujeito e uma das pesquisadoras, considerando as condições de sigilo e acústicas necessárias ao bom desenvolvimento das mesmas.

O registro das entrevistas foi feito com auxílio de um gravador, sendo as fitas posteriormente transcritas na íntegra. O material resultante da transcrição foi lido por diversas vezes, o que permitiu às pesquisadoras familiarizarem-se com a trajetória do sujeito da pesquisa. A análise desse material centrou-se no conteúdo das falas do sujeito, entendendo-se a análise de conteúdo como um conjunto de procedimentos que têm como objetivo a produção de um texto analítico em que se apresenta o corpo do texto de maneira transformada, transformação esta que se pauta em uma determinada fundamentação epistemológica (Navarro \& Díaz, 1994).

A fundamentação epistemológica norteadora da interpretação dos dados coletados foi o materialismo histórico e a dialética, mais especificamente as apropriações que são feitas pela psicologia histórico-cultural. Gonzalez Rey (1997) esclarece a possibilidade da aproximação entre análise de conteúdo e psicologia histórico-cultural à medida que se proceda a uma análise criteriosa que resulte em uma compreensão crítica e contextualizada das falas dos sujeitos com os quais se pesquisa, considerando seus aspectos objetivos e subjetivos.

\section{As concepsões de Nando sobre criatividade}

A respeito da relação do sujeito com a arte, investigação anterior (Vide Zanella, Da Ros, Reis \& França, 2003) revelou que Nando apresentava, quando do início das aulas, uma concepção de criatividade consoante com a que nortearia as reflexões no decorrer do semestre letivo, ainda que modificações tenham sido observadas ao final do processo, como veremos aqui.

"Pessoa criativa" significa para Nando capacidade de improvisar, originalidade e transformação de matéria bruta em objetos, processo em que a intuição ganha destaque. Concebe que criatividade pode ser produzida através de oficinas de sensibilização, de experiências diferentes, conhecendo povos, "entrando em contato com pessoas que são criativas e não vivendo num mundo apático onde todo mundo faz sempre a mesma coisa".

Nando destaca que, "no convívio com pessoas criativas, tu começa a ver o mundo de uma forma diferente... tu vai ver que a pessoa percebe umas coisas que tu nunca ia perceber." Concebe a criatividade também como improviso. "Fazendo arte o tempo todo, criatividade... eu não sei quando eu faço... faço meus improvisos..."

Desse modo, para ele a criatividade se produz a partir das/nas relações sociais, que é precisamente pela inserção num mundo significado e significativo, que se (re)faz pela ação humana ao longo de sua história, que a originalidade do artista criador se institui. Define-se como criativo porque faz suas coisas, não gosta de comprá-las prontas. Imprime seu estilo no que faz. Expressa uma concepção de arte ligada à vida, ao seu cotidiano.

Nando: seu percurso, suas histórias e as vozes que o acompanbam Vamos conhecer Nando buscando localizar em sua história indicadores que possibilitem compreender a dimensão estética, dimensão esta que, para nós, significa a possibilidade ou a concreta objetivação da subjetividade de forma sensível; ou seja, é a relação que o sujeito estabelece com os outros e com a realidade, permeada pela sensibilidade, numa vivência que se revela, ao mesmo tempo, reflexiva e afetiva. Essa dimensão esteve marcadamente presente nas atividades que Nando empreendeu no contexto de sala de aula.

Nando lembra de sua infância como período rico de imaginação e criatividade. Descreve uma infância ao ar livre com amigos, quando brincava com objetos transformados pela imaginação em outros objetos para apoiar histórias inventadas coletivamente: "Quando eu era criança adorava brincar muito com o imaginário... eu e os amigos do meu bairro, a gente inventava situações..."

Estas memórias de infância, narradas por Nando, impulsionam a refletir sobre as relações entre a realidade e a atividade imaginativa do sujeito, tal como explicitadas por Vygotski (1990). O referido autor destaca que uma das formas pelas quais se vinculam realidade e fantasia reside na extração de material que a imaginação opera sobre o mundo concreto. Em outras palavras, todo fruto da atividade imaginativa é formado a partir de fragmentos do real, tal como o sujeito o vivencia. Assim sendo, quanto maiores as possibilidades que o sujeito tiver de experimentar o mundo, mais elementos poderão estar a serviço da imaginação.

Dando continuidade a sua fala, Nando relata:

[...] Fazia bonequinhos de madeira ou até brincava com pedras e criava histórias pra esses personagens... colocava eles na cordilheira dos Andes, colocava eles no Egito, 
fazia eles descerem um rio e ficava bolando histórias... daí a gente mexia muito com a imaginação...

Outro modo de relação entre fantasia e realidade reside na possibilidade que desenvolve o ser humano de, mediado pelo outro, imaginar aquilo que não vivenciou diretamente. Vygotski (1990) destaca também que aquilo que a imaginação formata, conforma-se enquanto matéria, passando a existir no mundo concreto. Relembrando a narrativa de Nando, vê-se que, fisicamente presente em sua cidade de origem, ele deslocavase pelo mapa - seja para as areias quentes do Egito, ou rumo às gélidas cordilheiras dos Andes - em sua imaginação, concretizando-a, por exemplo, sob a forma de bonecos de madeira.

Este relato de momentos da infância faz lembrar ainda o estudo de Teplov (1977), o qual assinala que a atividade artística da criança desenvolve-se no jogo. Enquanto a atividade artística origina um produto, um resultado, os motivos do jogo se encontram no próprio processo da atividade e não no resultado. A proximidade das atividades parece estar na experiência emocional que elas produzem, pois arte e jogo infantil implicam experiência emocional, imaginação e processo ativo. São, portanto, atividades nas quais o sujeito envolve-se integralmente, propiciando momentos para assimilar, compreender, comunicar e objetivar emoções e sentimentos.

Fazer objetos ou transformar objetos nos jogos imaginários partilhados com amigos foi a primeira lembrança da infância apresentada por Nando. Nota-se que a imaginação aparece referida em um universo rico de informações que transcendem o aqui e agora, concreto vivido quando criança. Para Vygotski (1996), o desenvolvimento da imaginação enquanto processo psicológico superior caracteriza-se justamente pela possibilidade de partir da realidade material para dela descolar-se, transmutando o percebido. Soprando vida nas pedras e na madeira trabalhada, Nando e seus amigos transfiguravam a concretude da realidade sob o signo da invenção, produtora de múltiplos sentidos.

A literatura, principalmente através das aventuras infantis, aparece como manancial enriquecedor do fantasiar. Ao lembrar-se da infância, Nando busca compreender seu processo de criação:

Acho que era porque a gente lia bastante também... His-
torinhas bem infantis... de aventuras infantis tipo: Ilha do
Tesouro, Rio Turbulento, Histórias da Mata Virgem... são
livros de aventura pra criança, era isso que eu gostava, nada
de muita... literatura clássica não era o meu caminho.

A fala de Nando mostra que ele teve acesso a uma variedade de livros com conteúdos diversos e, importante destacar, voltados aos seus interesses naquele momento de sua existência, o que pode explicar o fato de serem lembrados tantos anos depois. Nesses livros nosso sujeito emergiu e imergiu de um outro modo, pois como esclarece Vygotski (1990, p. 25),

\section{a imaginação e a fantasia estão a serviço da esfera emo- cional. [...] A atividade da imaginação está estreitamente ligada ao movimento dos sentimentos. Ela é uma atividade muito rica em momentos emotivos.}

Em outro segmento da entrevista, Nando lembra as atividades artísticas que sua mãe realizava: "a mãe pintava, ela tocava violão... não me interessava mesmo, eu achava um saco aquilo".

A arte estava presente no meio em que Nando cresceu. A mãe é artista plástica. Quando criança, Nando ouvia música e via a mãe pintando. A atividade artística fazia parte do seu cotidiano. Nando conta que teve acesso a materiais e instrumentos (lápis, tinta, papel, tela) que o familiarizaram com a arte e lhe permitiram experimentar emoções estéticas desde muito cedo, mas inicialmente, ele não se mostrava atraído por tais atividades.

Porém, no tempo presente da entrevista, Nando se vê capaz de compreender sua história, dando inteligibilidade de seu interesse pela arte: "de repente tinha ficado essa mensagem da infância... ó isso me veio na cabeça agora... é de repente ficou... meio que gravado..."

Ao se reportar ao passado, chega a mencionar a mediação da mãe na aprendizagem das atividades e na avaliação que fazia delas: "tu tem que fazer isso, tu tem que pintar, teu desenho é bom, eu lembro que a mãe falava... é... só que eu não fazia. De repente, de uma hora pra outra, eu pensei: Pô, vou fazer."

A escola aparece em sua fala associada a um período de desinteresse generalizado. Nando lembra que não prestava atenção nas aulas, "ficava sempre fazendo uns rabiscos de canto de página, uns desenhinhos ... Eu odiava a escola. Não me sentia bem lá dentro."

A vivência na escola surge em sua memória como um período "nada criativo. $\mathrm{Na}$ época eu não estudava nada. Eu só ouvia e nem prestava atenção.” A oportunidade de participar de uma oficina de arte fora do espaço da escolarização formal, segundo Nando, foi determinante no desenvolvimento da dimensão criativa que permanecia adormecida na sala de aula.

...quando eu fir oficina de arte no CIC... era... uma professora que não desenvolvia a técnica, ela desenvolvia a criatividade mesmo, ela trabalhava com o desenvolvimento individual do aluno pra que ele desenvolvesse seu processo mesmo, criasse sua própria arte... 
Ainda que neste trecho Nando aponte para uma distância entre a "técnica" e a "criatividade", para Vygotski (1990) tais elementos articulam-se na atividade criadora. Isto porque os processos de criação implicam a experimentação material, o exercício de materializar a atividade imaginativa. Para concretizar uma obra, seja ela uma pintura ou composição musical, é preciso que além da idéia e do afeto, o artista se aproprie de um saber prático sobre pigmentos, movimentos do pincel ou notas musicais... Assim sendo, vemos que toda criação, por plasmar a singularidade de seu produtor, contempla igualmente as possibilidades do momento histórico vivido pelo artista. Ou seja, em toda e qualquer obra singular há "um coeficiente social [...] alguma colaboração anônima" (tradução nossa do espanhol, Vygotski, 1990, p. 38).

A participação nesta oficina de arte, para Nando, parece ter propiciado um espaço para o aprendizado de artifícios técnicos e contato com as produções de outros artistas. Nando segue comentando as propostas da professora de artes:

... a primeira coisa que ela [a professora] fez foi pedir pra que a gente levasse alguns desenhos[...] e a partir dali ela viu mais ou menos como que era o men trabalho. Dai ela disse pra en fazer alguns desenhos de observação, foi vendo como é que era o men traço... e a partir dai ela foi trazendo exemplos de artistas assim já antigos né de outras épocas que tinha algumas coisas parecidas com o men trabalho... ela dava essas opcões... e eu faria os trabalhos e dai ela via alguma coisa e sugeria, ela faria alguma questãozinha tipo... como se... se instigasse alguma coisa dentro de mim pra eu pensar ... ficar a noite inteira pensando e chegar no dia seguinte e me tocar assim "ah já sei o que tu tava querendo dizerer".

Interessante destacar o modo como a professora da oficina de arte partiu dos interesses de Nando e, deliberadamente, apresentou atividades que o provocaram a transformar tanto seu olhar quanto sua relação com a arte e o que produzia até então. Mais importante, respeitou sua expressão estética. O conhecimento por meio da observação de desenhos de artistas e a relação com a professora que mediava estas observações são lembrados como momentos motivadores para a reflexão sobre criação e percepção em arte. Vygotski (2001, p. 337) nos ajuda a compreender este processo quando escreve que

...ao percebermos uma obra de arte, nós sempre a recriamos de forma nova. É legitimo definir os processos de percepsão como processos de repetição e recriação do ato criador.

Num primeiro momento, notamos duas pessoas significativas nas lembranças de Nando, a mãe e a professora de arte, ainda que o reconhecimento da importância da primeira, enquanto mediadora para o seu próprio fazer artístico, apareça, em sua fala, de modo contraditório. Após afirmar acreditar que a criatividade pode ser incentivada, perguntamos se Nando achava que havia sido incentivado a criar, ao que ele respondeu: “...tem um certo histórico de arte na família... só que eles não me incentivaram..."

Em casa, no ateliê da mãe, tinha material de pintura como telas, tinta, etc. Logo em seguida afirma que foi estimulado somente de forma oral. "... eu acho que ficar só na palavra, não adiantou".

Pode-se pensar que, quando a mãe tocava violão, pintava e o estimulava a desenhar, além de dividir com ele momentos de afeto, preparou o caminho que mais tarde ele trilharia. Nando foi uma criança que muito cedo teve acesso a materiais de artes plásticas. Compartilhava com a mãe a pintura e a música, embora em um movimento de contraposição e negação. Inicialmente, afirma que não foi incentivado para as artes, para depois atribuir uma certa influência do ambiente familiar, especialmente na figura de sua mãe.

A fim de penetrar no âmago desta ambigüidade, é interessante retomar o relato de Nando, no ponto em que narra o processo que culminou em sua primeira pintura artística, quando aparece uma terceira pessoa como mediadora na sua constituição como artista:

\section{A primeira vez que eu pintei... foi por causa de um amigo meu... que é pianista... ele é um gênio no piano, fenomenal, estremeço quando ouço ele tocando. A gente tava na casa dele fazendo um improviso, eu tava tocando violão, ele no piano e outro no baixo... tocando um tempo [...] só que a gente se perdeu, ele continuou tocando e a gente parou... [fiquei] contemplando altas cara, fechei os olhos ... fiquei bem inspirado [...] cheguei em casa, tava com o corpo todo meio que em êxtase ainda... não tinha ninguém em casa, fui pro ateliê da mãe, tinha uma tela em branco lá, tinha as tintas... [eu] disse "ah, vou pintar"... fiquei umas três horas pintando... saiu um quadro... nunca tinha pintado e saiu mesmo, ali na minha frente, uma mulher correndo num campo numa chuva... e do nada...}

Além de ser contada por Nando com uma impressionante profundidade estética, tal experiência traz alguns elementos que podem nortear reflexões acerca de sua constituição como artista. O "estremecimento", fruto da relação estética entabulada com a improvisação musical, mais do que um efeito imediato arrebatador de sua emoção, mobilizou Nando por inteiro, em suas dimensões cognitiva, afetiva e corporal. Ultrapassando a duração de um momento, esta ebulição que desestabilizou Nando engendrou nele um movimento complexo no 
qual tomou forma o anseio de comunicar-se. Plasmado no produto de sua atividade criadora, Nando imprimiu à "tela branca" sua marca: expresso através da/na arte, o instante eternizado agora pertence ao mundo, às significações tão mutantes e variadas quanto os sujeitos que com a obra estabelecerem uma relação estética.

Porém, apreender a riqueza do quadro produzido implica cartografar, para além de seus elementos desencadeadores, toda a trajetória singular de Nando. Mesclam-se aí a criação lúdica e a mediação da literatura, com os companheiros de jogo da infância; a atividade artística com os amigos adolescentes; o malestar nas atividades de estudo e os desenhos "nos cantos" do caderno, nas bordas da anestesia escolar, e a mediação, mesmo que na recusa, do conhecimento adquirido neste contexto. Também a fala e o ato materno que incitavam à pintura e à música, mediação afetiva que se objetivava na arte, num movimento de aceitação e negação por parte de Nando; a participação na oficina de arte e a mediação "instigadora" da professora.

Finalmente, vê-se que a presença do fazer artístico em suas diferentes modalidades está traçada como constante no mapa da vida de Nando. Assim, embora ele pareça nem sempre significar/reconhecer seu cotidiano familiar como incentivador de sua objetivação, não se pode dissociar seu fazer artístico do contexto que foi atravessado pela música e pela pintura, a partir do/no qual se desenvolveu sua história. A mulher correndo no campo, sob a chuva, apesar da origem inusitada e/ou desconhecida que desponta no discurso de Nando - "saiu do nada..." -, se revela, como toda criação, um "catastrófico parto, conseqüência de uma longa gestação" (Vygotski, 1990, p. 31), mesmo que o sujeito não se reconheça neste processo.

À medida que seu envolvimento com a arte crescia, superando a dimensão do lazer, outras contradições emergiram. Nando menciona que na pintura foi incentivado pela mãe até o momento em que resolveu ser artista. Sua entrada numa banda musical despertou nos pais o medo de que fazer arte "... ia distrair dos estudos. No instrumento, na música, fui reprimido completamente.”

Nesta perspectiva, não só seu movimento em relação à mediação da família se fazia na dialética aceitação/negação, também o movimento da família em relação a suas objetivações artísticas se fazia num processo de ambigüidades.

Nando salienta que em nosso contexto social a arte é vista como lazer, hobby e não como trabalho, já que é concebida como "coisa de vagabundo". Revelou como a concepção negativa de arte determinou o abandono, por algum tempo, da atividade artística. “...teve época que abandonei tudo, não queria mais pintar, eu não escrevia, não fazia mais nada." Mas, em outro momento de sua vida, Nando parece buscar tomar a arte como Psico-USF, v. 10, n. 2, p. 191-199, jul./ dez. 2005 uma atividade possível em sua existência: "só que eu voltei... agora tô legal, tô massa. Eu parei de tocar... de fazer música... mas eu comecei a pintar, comecei a escrever literatura."

Aqui devemos pensar como a concepção de arte presente na sociedade é subjetivada, sendo, muitas vezes, determinante na constituição de crianças e jovens que constroem o projeto de ser artista. Como a visão de arte como "supérflua", "simples objeto de prazer hedonista ou decorativo", participa muitas vezes da construção do projeto de jovens que se aproximam da arte, tanto para aqueles que a reproduzem, quanto para aqueles que a superam e conseguem, apesar deste preconceito, transcender-se em artistas profissionais. Os sujeitos, nesta perspectiva, se objetivam dialetizando as contradições, em alternativas ou caminhos possíveis, de acordo com seu contexto específico.

Nando dialetiza esta contradição, afirmando aproximar o fazer artístico do científico e reconhecendo que se projeta por meio do modo como articula singularmente das palavras e seus significados na elaboração de seus trabalhos acadêmicos. Mesmo durante o período em que diz ter se afastado da arte, trouxe elementos estéticos, dessa vez literários, para seu cotidiano na universidade. A relação com a ciência, entretanto, nem sempre esteve livre de conflitos: um momento agudo de "crise" culminou num afastamento, ainda que temporário, do curso de psicologia.

As formas que o sujeito encontra, para a superação das contradições, não se processa de maneira linear. Ela se dá por avanços e recuos, por afirmações e negações, traduzindo-se num movimento em espiral, onde o sujeito parece reviver velhos dilemas, mas os enfrenta em diferentes níveis de complexidade. Para Nando, no período das entrevistas, arte e ciência estavam novamente entrelaçadas. "Faz 6 a 7 anos que eu mexo com arte... violão uns 10 anos... pintura, literatura... escultura um pouco... eu toco um pouco de flauta... um pouco de vídeo, fotografia.”

Pelo trânsito constante nas diversas linguagens artísticas, Nando destaca que a criatividade se localiza numa esfera ainda mais ampla que os diferentes campos da arte, abarcando o ensino, o cotidiano... enfim, a vida humana: "...a criatividade é essencial para o ser humano... para o ser humano se tornar humano..."

Nesta perspectiva, a atividade criadora, além da transmutação da natureza, do "improviso" que modifica a realidade, implica a constituição de humanidade para o sujeito criador.

Quando perguntado o que seria para ele uma pessoa criativa, responde: “...não fica só nas citações, coloca um pouco da sua subjetividade... pensamento... improvisa... idéias que as outras pessoas nunca tiveram... pegar um pedaço de madeira e transformar num objeto útil.” 


\section{Considerações finais}

Nos processos de criação artística, o ser humano se objetiva e subjetiva, transformando realidades, criando significados para si e para os outros. A arte é criação especial na medida em que tem como função primordial a constituição e expressão do humano nas coisas. Isso porque a matriz da qual se nutre a arte é a vida humana; a atividade artística, em sua forma e conteúdos, plasma num produto o mundo em relação ao homem, que o metamorfoseia em símbolos. É somente numa realidade social coletivamente significada e significativa que criar artisticamente faz sentido. $\mathrm{O}$ artista se reconhece na obra que produz, condensando toda a humanidade que jorra nele/ dele, em algo que pode ser apreendido pelos demais e que se revela como testemunha da capacidade humana de apoiar-se na concretude para transmudá-la, atribuindo-lhe propriedades que, sem o olhar humano, ela não possui.

Esse movimento, a história de Nico aqui apresentada permitiu revelar, pois por meio dela pudemos compreender a gênese do processo de criação e situá-la em um contexto específico, apontando o caráter coletivo na sua vida singular. Além disso, ao identificar seus mediadores, é possível reconstruir objetivações vividas, por meio de suas falas, gestos, ações e escolhas, para em seguida identificar o que Nando pôde fazer com elas, de que sentidos conseguiu se apropriar, que outros foi destacando, que outros foi negando e se apropriando ao mesmo tempo.

$\mathrm{O}$ que ele fez com tudo que viveu até então? $\mathrm{O}$ modo como busca a articulação entre arte e ciência não é aleatório, pois traduz a maneira como ele supera seus sentidos na produção de novos sentidos para suas atividades, ou seja, a maneira como uma subjetividade supera a objetividade em direção a uma nova subjetividade.

Se ao lado de Sawaia afirmarmos que "conhecimento, ação e afetividade são elementos de um mesmo processo, o de orientar a relação do homem com o mundo e com o outro" (1994, p. 164), podemos fechar provisoriamente estas reflexões acerca do processo criativo, apontando para o fato de que a criação exige estes três elementos para se fazer atividade verdadeiramente humana. Sendo social e coletiva em princípio, seu destino é passar por um processo árduo e bastante complexo, até que se faça singular e diferenciada em um contexto repleto de experiências e sentidos múltiplos.

\section{Referências}

González Rey, F. (1997). Epistemología cualitativa y subjetividad. São Paulo: EDUC.

Japiassu, R. O. V. (1999). As artes e o desenvolvimento cultural do ser humano. Educação \& Sociedade, 69(20), 34-59.

Maheirie, K. (2002). Constituição do sujeito, subjetividade e identidade. Revista Interaçôes, 13(7), 31-44.

Maheirie, K. (2003). Processo de criação no fazer musical: uma objetivação da subjetividade, a partir dos trabalhos de Sartre e Vygotsky. Psicologia em Estudo, 2(8), 147-153.

Morin, E. (1996). A noção de sujeito. Em Schnitman, D. F. (Org.). Novos paradigmas, cultura e subjetividade (pp. 45-58). Porto Alegre: Artes Médicas.

Navarro, P. \& Díaz, C. (1994). Análisis de contenido. Em J. M. Delgado \& J. Gutiérrez Métodos y técnicas cualitativas de investigación en ciencias sociales (pp. 177223). Madri: Síntesis.

Neves, W. M. J. (1997). As formas de significação como mediação da consciência: um estudo sobre o movimento da consciência de um grupo de professores (Tese de Doutorado). São Paulo: Pontifícia Universidade Católica -PUC.

Olabuénaga, J. I. R. (1999). Metodología de la investigación cualitativa. Bilbao: Universidad de Deusto.

Sánchez Vázquez, A. (1999). Convite à estética. Rio de Janeiro: Civilização Brasileira.

Sartre, J. P. (1965). Esboģo de uma teoria das emocões (F. de C. Ferro, Trad.). Rio de Janeiro: Zahar (Trabalho original publicado em 1939).

Sartre, J. P. (1984). Questão de método. Em Os Pensadores (pp. 109-191) (B. Prado Jr., Trad.). São Paulo: Abril Cultural (Trabalho original publicado em 1960).

Sawaia, B. B. (1994). Dimensão ético-afetiva da classe trabalhadora. Em S. T. M. Lane \& B. B. Sawaia (Orgs.). Novas veredas da psicologia social (pp. 157-168). São Paulo: Brasiliense.

Teplov, R. M. (1977). Aspectos psicológicos de educação artística. Em Psicologia e pedagogia. II. Lisboa: Estampa.

Vygotski, L. S. (1987). Historia del desarrollo de las funciones psiquicas superiores. Ciudad de La Habana: Editorial Científico-Técnica.

Vygotski, L. S. (1990). La imaginación y el arte en la infancia. Madri: AKAL.

Vygotski, L. S. (1991). Obras escogidas I. Madri: Visor.

Vygotski, L. S. (1995). Obras escogidas III: problemas del desarrollo de la psique. Madri: Visor.

Vygotski, L. S. (1996). Obras escogidas IV. Madri: Visor.

Vygotski, L. S. (1998). Psicologia da arte. São Paulo: Martins Fontes. 
Vygotski, L. S. (2001). Psicologia pedagógica. São Paulo: Martins Fontes.

Zanella, A. V., Balbinot, G. \& Pereira, R. S. (2000). Recriar a (na) renda de bilro: analisando a nova trama tecida. Psicologia: Reflexão e Crítica, 3(13), 539-547.

Zanella, A. V., Ros, S. Z., Reis, A. C. \& Franca, K. B. (2003). Concepções de criatividade: movimentos em um contexto de escolarização formal. Psicologia em Estudo, 1(8), 143-150.

Sobre as autoras:

Andréa Vieira Zanella é doutora em Psicologia da Educação pela PUC/SP, docente do Departamento de Psicologia e do Programa de Pós-Graduação em Psicologia da UFSC, bolsista de produtividade do CNPq.

Alice Casanova dos Reis é psicóloga formada pela UFSC.

Denise de Camargo é doutora em Psicologia Social pela PUC/SP, docente do Programa de Pós-Graduação em Psicologia da UFPR.

Kátia Maheirie é doutora em Psicologia Social pela PUC/SP, docente do Departamento de Psicologia e do Programa de Pós-Graduação em Psicologia da UFSC.

Kelly Bedin França é mestranda do Programa de Pós-Graduação em Psicologia da UFSC.

Silvia Zanatta Da Ros é doutora em Psicologia da Educação pela PUC/SP, docente do Programa de PósGraduação em Educação da UFSC. 


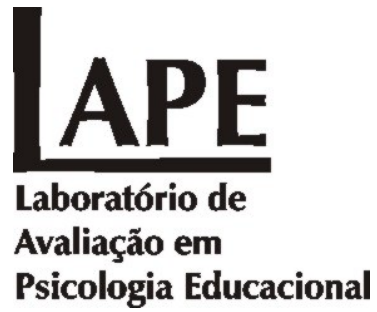

Programa de Pós-Graduação Stricto Sensu em Psicologia da Universidade São Francisco

Estudo de instrumentos de avaliação de processos cognitivos e afetivos envolvidos em situações de aprendizagem nos diversos contextos de escolarização. Envolve a participação de doutorandos, mestrandos e bolsistas de Iniciação Científica.

Professores responsáveis:

Dra. Acácia Aparecida Angeli dos Santos

acacia.santos@saofrancisco.edu.br

Dr. Fermino Fernandes Sisto

fermino.sisto@saofrancisco.edu.br

Dra. Maria Cristina Rodrigues de Azevedo Joly maria.joly@saofrancisco.edu.br 